\title{
Comparison and rapid prediction of lignocellulose and organic elements of a wide variety of rice straw based on near infrared spectroscopy
}

\author{
Abdoulaye Aguibou Diallo ${ }^{1,2}$, Zengling Yang ${ }^{1}$, Guanghui Shen ${ }^{1}$, Jinyi Ge ${ }^{1}$, Zichao Li ${ }^{3}$, Lujia Han $^{1 *}$ \\ (1. College of Engineering, China Agricultural University, Beijing 100083, China; \\ 2. Higher Institute of Agronomic and Veterinary "Valery Giscard d'Estaing”, Faranah 131, Guinea; \\ 3. College of Agronomy and Biotechnology, China Agricultural University, Beijing 100094, China)
}

\begin{abstract}
Rice straw is a major kind of biomass that can be utilized as lignocellulosic materials and renewable energy. Rapid prediction of the lignocellulose (cellulose, hemicellulose, and lignin) and organic elements (carbon, hydrogen, nitrogen, and sulfur) of rice straw would help to decipher its growth mechanisms and thereby improve its sustainable usages. In this study, 364 rice straw samples featuring different rice subspecies (japonica and indica), growing seasons (early-, middle-, and late-season), and growing environments (irrigated and rainfed) were collected, the differences among which were examined by multivariate analysis of variance. Statistic results showed that the cellulose content exhibited significant differences among different growing seasons at a significant level $(p<0.01)$, and the contents of cellulose and nitrogen had significant differences between different growing environments $(p<0.01)$. Near infrared reflectance spectroscopy (NIRS) models for predicting the lignocellulosic and organic elements were developed based on two algorithms including partial least squares (PLS) and competitive adaptive reweighted sampling-partial least squares (CARS-PLS). Modeling results showed that most CARS-PLS models are of higher accuracy than the PLS models, possibly because the CARS-PLS models selected optimal combinations of wavenumbers, which might have enhanced the signal of chemical bonds and thereby improved the predictive efficiency. As a major contributor to the applications of rice straw, the nitrogen content was predicted precisely by the CARS-PLS model. Generally, the CARS-PLS models efficiently quantified the lignocellulose and organic elements of a wide variety of rice straw. The acceptable accuracy of the models allowed their practical applications.
\end{abstract}

Keywords: rice straw, near infrared reflectance spectroscopy models, rapid prediction, competitive adaptive reweighted sampling, partial least-squares, lignocellulose

DOI: $10.25165 /$ j.ijabe.20191202.4374

Citation: Diallo A A, Yang Z L, Shen G H, Ge J Y, Li Z C, Han L J. Comparison and rapid prediction of lignocellulose and organic elements of a wide variety of rice straw based on near infrared spectroscopy. Int J Agric \& Biol Eng, 2019; 12(2): $166-172$.

\section{Introduction}

As an important biomass that can be utilized as fertilizers, feed, renewable energy, and lignocellulosic materials, approximately 1.11 billion tons of rice straw was produced annually across the world. China is one of the largest rice straw producers who accounts for more than $28 \%$ of the total production ${ }^{[1]}$. Quantification of the most important compositions of rice straw, such as lignocellulose and organic elements, could help to decipher the inherent nature of rice straw during its growth and thereby benefit to breeding programs and crop yields. Furthermore, an illustration of the variations in these compositions among different rice straw varieties would contribute to establish animal feed formulas, precisely assess greenhouse gas emissions from rice fields, and promote renewable energy ${ }^{[2-5]}$.

\section{Received date: 2018-05-09 Accepted date: 2019-03-12}

Abdoulaye Aguibou Diallo, $\mathrm{PhD}$, interests: animal production., Email: aguibouisav2003@yahoo.fr; Zengling Yang, Professor, interests: biomass engineering, Email: yangzengling@163.com; Guanghui Shen, PhD, interests: non-destructive testing of agricultural products, Email: shenguanghui@ cau.edu.cn; Jinyi Ge, PhD, interests: biomass engineering, Email: gejinyi@ cau.edu.cn; Zichao Li, Professor, interests: rice seed resources and genomics, Email: lizichao@cau.edu.cn.

*Corresponding author: Lujia Han, $\mathrm{PhD}$, Professor, research interests: biomass engineering, College of Engineering, China Agricultural University, Beijing 100083, China. Tel/Fax: +86-10-62736313, Email: hanlj@cau.edu.cn.
The lignocellulose of rice straw contains cellulose (Cel), hemicellulose (Hem), and lignin ( $\mathrm{Lig})$, while the organic elements mainly include carbon $(\mathrm{C})$, hydrogen $(\mathrm{H})$, nitrogen $(\mathrm{N})$, and sulphur (S). They might vary significantly with different rice subspecies, growing seasons, and growing environments. In China, the major rice subspecies are Japonica rice and Indica rice. Japonica rice is often found in the cooler areas of subtropics and temperate zones. Indica rice is usually grown in the hot climates of tropics and subtropics. The growing seasons of rice include early-season, middle-season, and late-season. The growing environments of rice can be classified as irrigated and rain fed based on water sources.

Traditionally, the contents of lignocellulose and organic elements are analyzed by wet-chemical analysis methods. For example, National Renewable Energy Laboratory (NREL) and Van Soest methods were used to examine the lignocellulosic contents of crops $^{[6]}$. The Van Soest method is an indirect method to calculate the lignocellulosic contents from neutral detergent fiber (NDF), acid detergent fiber (ADF), and acid detergent lignin (ADL), while the NREL method is considered a direct measurement by determining the carbohydrate content after hydrolysis ${ }^{[6]}$. However, both of these conventional methods are time-consuming, labour-intensive, expensive, and destructive. Therefore, near infrared reflectance spectroscopy (NIRS), as a rapid, cost-effective, and non-destructive analytical strategy, has become a hotspot. Its principle is based on the correlation between the vibration of 
chemical bonds and the absorption of electromagnetic radiation at different wavenumbers. However, the lignocellulosic data for the existing NIRS models for rice straw were obtained by the indirect calculation of the Van Soest method rather than the NREL method $^{[2-5]}$. Additionally, there is litter literature concerning the development of NIRS models for a wide variety of rice straw.

The purpose of current study was to investigate the variation of lignocellulose and organic elements of rice straw related to different rice subspecies, growing seasons, and growing environments, and explore the feasibility of using NIRS to quantify and predict the lignocellulose and organic elements of a wide variety of rice straw. The results of the study were expected to benefit the scientific understanding and utilization of rice straw.

\section{Materials and methods}

\subsection{Wet-chemical analysis}

\subsubsection{Lignocellulose}

The contents of Cel, Hem, and Lig of the milled samples were measured in duplicate according to the NREL methods ${ }^{[6]}$. Briefly, each sample $(0.30 \mathrm{~g})$ and deionized water $(10 \mathrm{~mL})$ were fully mixed and extracted in a boiling water bath to remove soluble sugar, then hydrolysed with $72 \%$ sulphuric acid. The mixture was diluted with deionized water and placed at $121^{\circ} \mathrm{C}$ for $1 \mathrm{~h}$. A portion of the supernatant was neutralized and filtered. The filtered liquid was detected by high performance liquid chromatography using a polymer column (Aminex HPX-87P, Bio-Rad, USA) with a refractive index detector (L-2490, Hitachi, Japan) to calculate the Cel and Hem contents, while the precipitate was used to detect the Lig content.

\subsubsection{Organic elements}

The contents of $\mathrm{C}, \mathrm{H}, \mathrm{N}$, and $\mathrm{S}$ of the milled samples were determined in duplicate by an elemental analyzer (Vario EL II, Elementar, Germany).

\subsection{Collection and preparation of rice straw samples}

All rice crops were grown from April 2013 to November 2014 in Yacheng town and Sanya City of Hainan province in South China. A total of 364 rice straw samples (roots and husk were not included) were collected just after harvesting. Among them, 208 samples were recorded with all information including rice subspecies, growing seasons, and growing environments. Another 156 samples were recorded with partial information or no information.

All the samples were cut to nearly $50 \mathrm{~mm}$ in length using a rubbing and cutting machine, thoroughly blended, oven-dried at $45^{\circ} \mathrm{C}$ for $24 \mathrm{~h}$, milled by a hammer mill (RT-34, Rong Tsong Precision Technology Co., Taiwan), sieved through a $2 \mathrm{~mm}$ sieve, and stored in zipper bags. All the bags were stored in a dry and shaded location for wet-chemical and spectral analysis.

\subsection{Statistical analysis}

The differences in Cel, Hem, Lig, C, H, N, and S among different rice straw were quantified by multivariate analysis of variance with statistical software (SPSS 17.0, SPSS Inc., USA). The significance level was noted as $p$.

\subsection{Near infrared reflectance spectroscopy (NIRS) analysis}

The milled rice straw sample $(15 \mathrm{~g})$ was placed in a standard sample cup and then scanned in a reflection mode using a Fourier transform infrared spectrometer (Spectrum 400, PerkinElmer, USA). The spectra were collected from $10000 \mathrm{~cm}^{-1}$ to $4000 \mathrm{~cm}^{-1}$ at a resolution of $8 \mathrm{~cm}^{-1}$. Each spectrum was the average of 32 scans. Each sample was analyzed three times, and the three spectra were averaged for further analysis.

\subsection{NIRS modelling}

\subsubsection{Model development}

Firstly, mathematical pretreatments were applied to the raw spectra, including standard normal variate (SNV), detrend, smoothing, multiple scatter correction (MSC), and autoscale ${ }^{[7]}$. SNV was applied to correct the effects of multiplicative interferences of scatter and particle size. Detrend would remove the linear and quadratic curvature of each spectrum. Smoothing would filter out noise interference. MSC was conducted for normalization. Autoscale was used for scaling and centering. Subsequently, a common algorithm, partial least-squares (PLS) regression, was used to develop NIRS models ${ }^{[8]}$. During calibration, leave-one-out cross-validation was performed. During cross-validation, one sample was kept out of the calibration dataset and used for prediction. Finally, the competitive adaptive reweighted sampling (CARS) algorithm was applied to select key wavenumbers from the full spectrum, extract pertinent signals, and minimize irrelevant signals from the spectra, which would help to establish a clearer correlation between the contents and the absorbance of chemical compositions. The number of Monte Carlo Sampling, the maximum number of partial least square components to extract, the number of folds for cross validation, and the method of data pretreatment were set to $50,10,5$, and auto scaling, respectively. All spectral pretreatments were performed using mathematical software (MATLAB 2013b, MathWorks, MA, USA) with a PLS toolbox (version 8.0, Eigenvector Research, WA, USA).

\subsubsection{Model evaluation}

The NIRS models were run with calibration and validation datasets. The following evaluation parameters were calculated: coefficient of determination for calibration $\left(R_{\mathrm{cal}}^{2}\right)$, root mean squared error of calibration (RMSEC), coefficient of determination for cross-validation $\left(R_{\mathrm{cv}}^{2}\right)$, root mean squared error of cross-validation (RMSECV), root mean squared error of prediction (RMSEP), and the ratio of RMSECV to the mean content (RSD).

\section{Results}

\subsection{Statistics of wet-chemical analysis}

The contents of lignocellulose and organic elements of 364 rice straw samples were examined by wet-chemical analysis. The statistic results of lignocellulose and organic elements of 364 rice straw samples, 208 samples for variance analysis and NIRS calibration and 156 samples for NIRS outside validation are shown in Table 1.

As listed in Table 2, the differences of lignocellulose and organic elements related to different subspecies, growing seasons, and growing environments were tested by multivariate analysis of variance. Only the Cel content had significant differences among different growing seasons and between different growing environments. The $\mathrm{N}$ content had significant differences between different growing environments. For different growing seasons, the Cel content in the late-season rice straw $(409.4 \pm 37.0 \mathrm{mg} / \mathrm{g})$ is significantly higher than that in the early-season rice straw $(397.1 \pm 27.5 \mathrm{mg} / \mathrm{g})(p<0.01)$. For different growing environments, the Cel content in rain fed rice straw $(421.7 \pm 32.6 \mathrm{mg} / \mathrm{g})$ is higher than that in irrigated rice straw $(399.7 \pm 32.3 \mathrm{mg} / \mathrm{g}) \quad(p<0.01)$. However, the $\mathrm{N}$ content in rain fed rice straw $(13.2 \pm 2.0 \mathrm{mg} / \mathrm{g})$ is lower than that in irrigated rice straw $(15.3 \pm 2.5 \mathrm{mg} / \mathrm{g})(p<0.01)$. 
Table 1 Contents of the lignocellulose and organic elements of rice straw

\begin{tabular}{|c|c|c|c|c|c|c|c|}
\hline \multirow{2}{*}{ Samples } & \multicolumn{3}{|c|}{ Lignocellulose $/ \mathrm{mg} \cdot \mathrm{g}^{-1}$} & \multicolumn{4}{|c|}{ Organic elements $/ \mathrm{mg} \cdot \mathrm{g}^{-1}$} \\
\hline & Cel & Hem & Lig & $\mathrm{C}$ & $\mathrm{H}$ & $\mathrm{N}$ & $S$ \\
\hline All samples $(n=364)$ & $398.9 \pm 30.6$ & $147.5 \pm 19.3$ & $154.4 \pm 20.8$ & $398.4 \pm 10.2$ & $49.6 \pm 2.8$ & $15.3 \pm 2.5$ & $3.8 \pm 0.5$ \\
\hline For variance analysis and NIRS calibration $(n=208)$ & $401.9 \pm 32.9$ & $147.6 \pm 20.8$ & $154.8 \pm 15.5$ & $398.1 \pm 9.5$ & $48.9 \pm 1.8$ & $15.1 \pm 2.5$ & $3.7 \pm 0.4$ \\
\hline For NIRS outside validation $(n=156)$ & $395.0 \pm 26.9$ & $147.4 \pm 17.2$ & $153.9 \pm 26.4$ & $398.7 \pm 11.1$ & $50.6 \pm 3.5$ & $15.5 \pm 2.4$ & $3.9 \pm 0.4$ \\
\hline
\end{tabular}

Note: Cel, cellulose; Hem, hemicellulose; Lig, lignin; C, carbon; H, hydrogen; N, nitrogen; S, sulphur; $n$, sample quantity; each value represents mean \pm standard error.

Table 2 Significant level $(p)$ of multivariate analysis of variance for the contents of lignocellulose and organic elements of rice straw

\begin{tabular}{|c|c|c|c|c|c|c|c|c|}
\hline & & Cel & Hem & Lig & $\mathrm{C}$ & $\mathrm{H}$ & $\mathrm{N}$ & $\mathrm{S}$ \\
\hline \multicolumn{2}{|c|}{ Homogeneity of variance test } & 0.074 & 0.232 & 0.181 & 0.249 & $0.012^{\mathrm{a}}$ & 0.077 & 0.150 \\
\hline \multicolumn{9}{|c|}{ Multivariate analysis of variance } \\
\hline \multirow{3}{*}{ Main effects } & Rice subspecies & 0.463 & 0.797 & 0.882 & 0.875 & / & 0.991 & 0.420 \\
\hline & Growing seasons & $0.008^{* *}$ & 0.222 & 0.167 & 0.425 & / & 0.078 & 0.411 \\
\hline & Growing environments & $0.032^{*}$ & 0.913 & 0.238 & 0.602 & / & $0.021^{*}$ & 0.280 \\
\hline \multirow{4}{*}{ Interaction effects } & Rice subspecies $\times$ Growing seasons & 0.206 & 0.680 & 0.802 & 0.940 & I & 0.681 & 0.901 \\
\hline & Rice subspecies $\times$ Growing environments & 0.225 & 0.644 & 0.166 & 0.509 & / & 0.595 & 0.286 \\
\hline & Growing seasons $\times$ Growing environments & $0.019^{*}$ & 0.186 & 0.483 & 0.889 & I & 0.294 & 0.269 \\
\hline & Rice subspecies $\times$ Growing seasons $\times$ Growing environments & 0.387 & 0.294 & 0.908 & 0.995 & I & 0.841 & 0.455 \\
\hline
\end{tabular}

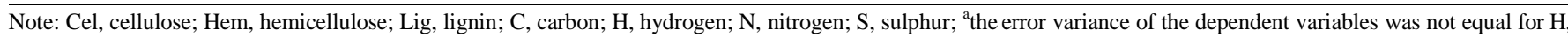
so the variance test for $\mathrm{H}$ was not run; ${ }^{*} p<0.05 ;{ }^{* *} p<0.01$.

\subsection{NIR spectra of rice straw samples}

The raw NIRS spectra of 364 rice straw samples are given in Figure 1. The spectra in the region of $10000-9000 \mathrm{~cm}^{-1}$ were

nearly flat, indicating that the baseline shift was effectively corrected by the mathematical pretreatments. The main absorption peaks of rice straw are also marked in Figure 1.

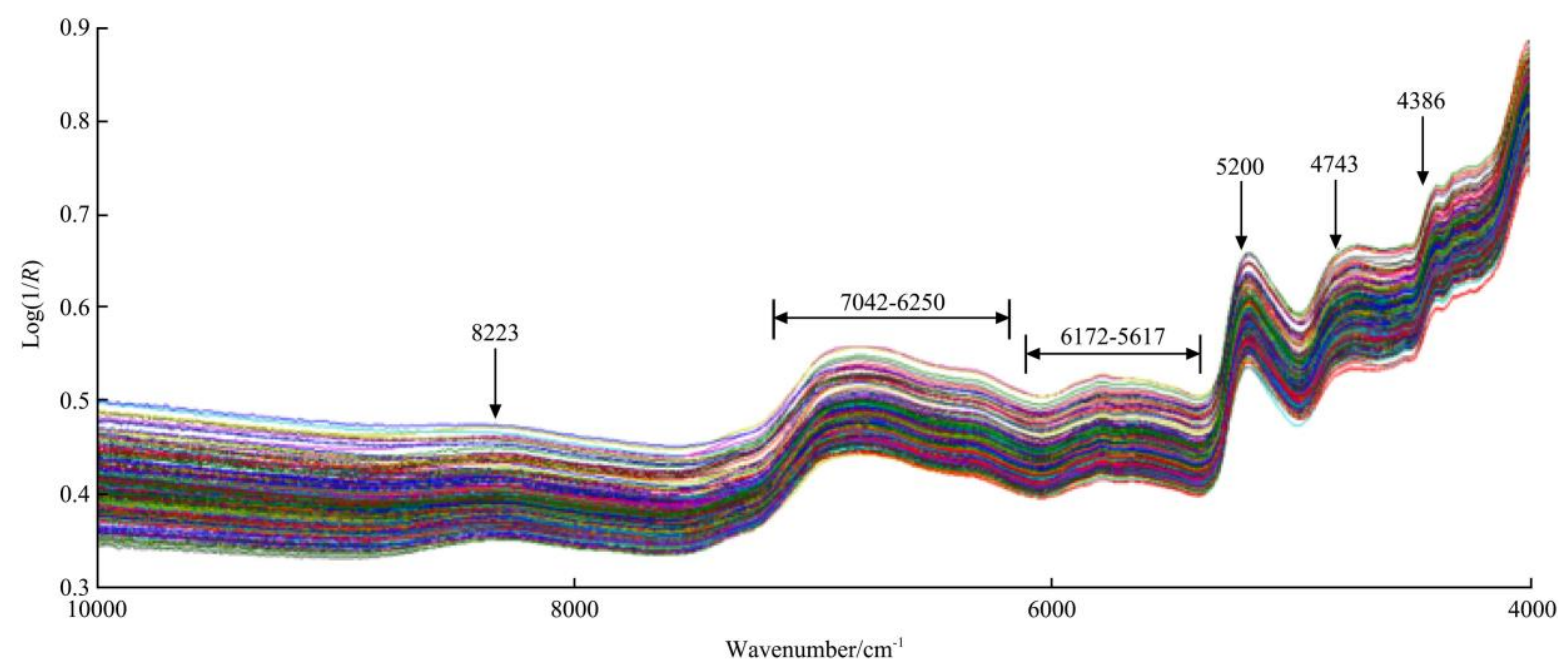

Figure 1 Raw near infrared spectra of rice straw samples

\subsection{NIRS modelling}

PLS models were performed on full spectra with 3001 wavenumbers for lignocellulose and organic elements and the modelling results are presented in Table 3. Rice straw is a complex natural matrix, and the spectra of rice straw include rich compound information. Furthermore, there were a lot of influencing factors during scanning the spectra. Therefore, the spectra had many redundant and interferential information. To address this problem and improve the precision of NIRS models, the CARS method was used to select optimal combinations of wavenumbers, and then combined with PLS to build CARS-PLS models based on the optimal combinations.
The optimal combinations of wavenumbers selected by CARS and the results of the CARS-PLS models for lignocellulose are shown in Figure 2. The Cel content in the rain fed rice straw is significantly higher than that of the irrigated rice straw. The Cel content in the early-season rice straw is significantly lower than in late-season rice straw. The rain fed rice straw distributed in the higher range, while the irrigated rice straw distributed in the lower range.

The optimal combinations of wavenumbers selected by CARS and the results of the CARS-PLS model for organic elements are shown in Figure 3. It can be seen that the $\mathrm{N}$ content in the rain fed rice straw is significantly lower than that in the irrigated rice straw. 
Table 3 Calibration and validation results of the NIRS models for the lignocellulose and organic elements of rice straw

\begin{tabular}{|c|c|c|c|c|c|c|c|c|c|}
\hline Contents & Models & Pretreatment methods & $\begin{array}{l}\text { Wavenumber } \\
\text { quantity }\end{array}$ & $\begin{array}{l}\text { PLS } \\
\text { factors }\end{array}$ & $R_{\text {cal }}^{2}$ & $\begin{array}{l}R M S E C \\
/ \mathrm{mg}^{-\mathrm{g}^{-1}}\end{array}$ & $R_{\mathrm{cv}}^{2}$ & $\begin{array}{l}R M S E C V \\
/ \mathrm{mg}^{-\mathrm{g}^{-1}}\end{array}$ & $\begin{array}{l}R M S E P \\
/ \mathrm{mg}^{-} \mathrm{g}^{-1}\end{array}$ \\
\hline \multirow{2}{*}{ Cel } & PLS & SNV, smoothing, autoscale & 3001 & 8 & 0.43 & 24.9 & 0.26 & 28.7 & 26.0 \\
\hline & CARS-PLS & SNV, smoothing, autoscale & 62 & 6 & 0.36 & 26.3 & 0.27 & 28.2 & 25.4 \\
\hline \multirow{2}{*}{ Hem } & PLS & SNV, smoothing, autoscale & 3001 & 5 & 0.10 & 19.7 & 0.03 & 20.6 & 17.9 \\
\hline & CARS-PLS & SNV, smoothing, autoscale & 131 & 9 & 0.35 & 16.7 & 0.23 & 18.3 & 22.7 \\
\hline \multirow{2}{*}{ Lig } & PLS & SNV, smoothing, autoscale & 3001 & 8 & 0.31 & 12.8 & 0.18 & 14.2 & 13.0 \\
\hline & CARS-PLS & SNV, smoothing, autoscale & 53 & 14 & 0.61 & 9.7 & 0.48 & 11.3 & 14.1 \\
\hline \multirow{2}{*}{$\mathrm{C}$} & PLS & SNV, detrend, smoothing, autoscale & 3001 & 8 & 0.64 & 5.7 & 0.48 & 6.9 & 7.7 \\
\hline & CARS-PLS & SNV, detrend, smoothing, autoscale & 53 & 8 & 0.77 & 4.5 & 0.72 & 5.0 & 8.1 \\
\hline \multirow{2}{*}{$\mathrm{H}$} & PLS & SNV, smoothing, autoscale & 3001 & 7 & 0.43 & 1.2 & 0.33 & 1.3 & 3.6 \\
\hline & CARS-PLS & SNV, smoothing, autoscale & 72 & 11 & 0.57 & 1.1 & 0.44 & 1.2 & 3.4 \\
\hline $\mathrm{N}$ & PLS & SNV, detrend, smoothing, autoscale & 3001 & 8 & 0.82 & 1.0 & 0.75 & 1.3 & 1.5 \\
\hline \multirow{2}{*}{$\mathrm{S}$} & PLS & MSC, autoscale & 3001 & 5 & 0.19 & 0.4 & 0.06 & 0.4 & 0.5 \\
\hline & CARS-PLS & MSC, autoscale & 113 & 12 & 0.64 & 0.3 & 0.35 & 0.4 & 0.5 \\
\hline
\end{tabular}

Note: NIRS, near infrared reflectance spectroscopy; Cel, cellulose; Hem, hemicellulose; Lig, lignin; C, carbon; H, hydrogen; N, nitrogen; S, sulphur; PLS, partial least squares; CARS, competitive adaptive reweighted sampling; SNV, standard normal variate; MSC, multiple scatter correction; $R_{\text {cal }}^{2}$, coefficient of determination for calibration; RMSEC, root mean squared error of calibration; $R_{\mathrm{cv}}^{2}$, coefficient of determination for cross-validation; $R M S E C V$, root mean squared error of cross-validation; $R M S E P$, root mean squared error of prediction.
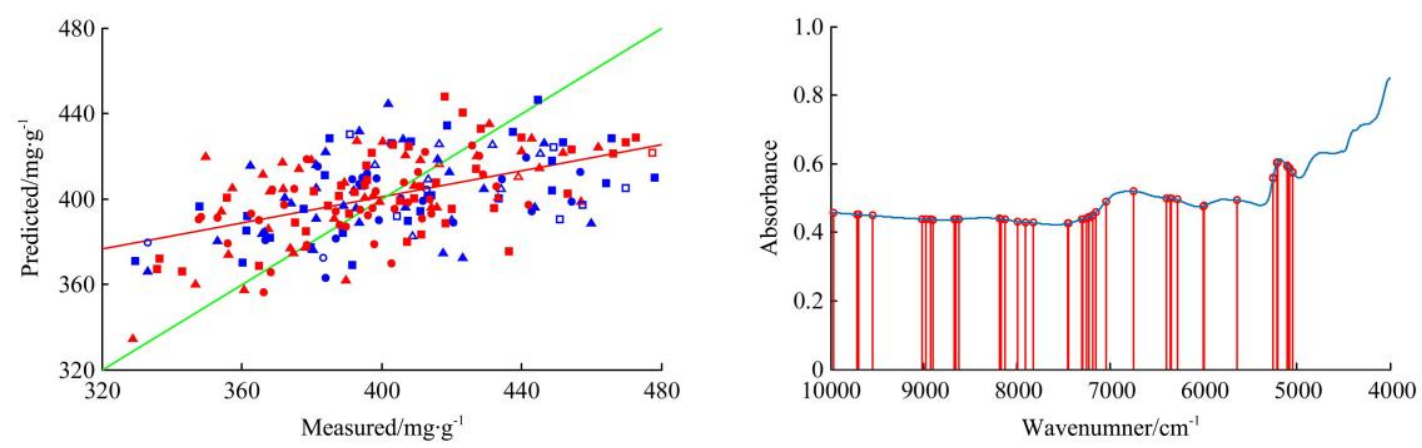

a. Cellulose
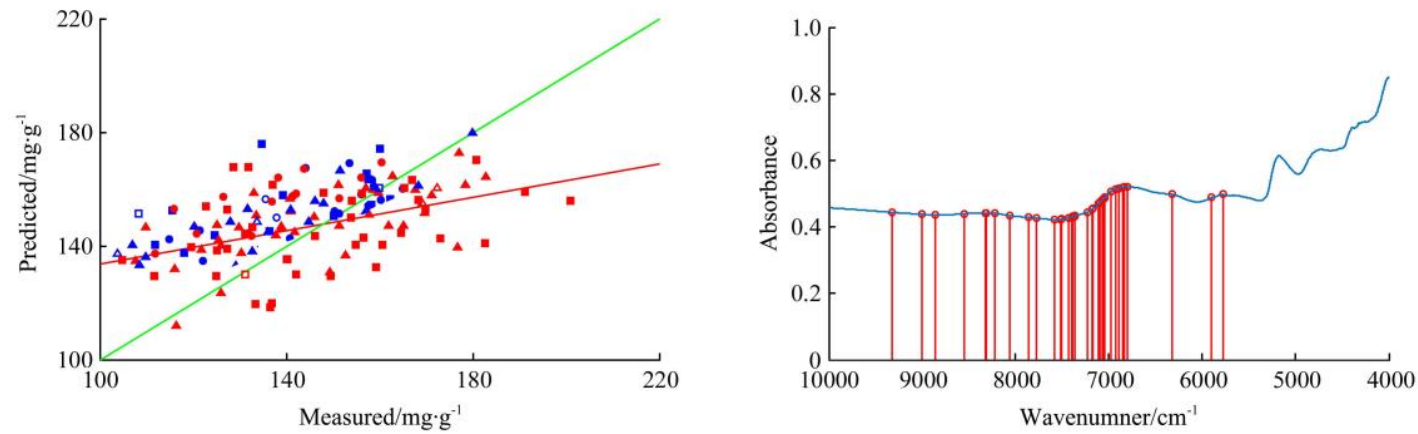

b. Hemicellulose
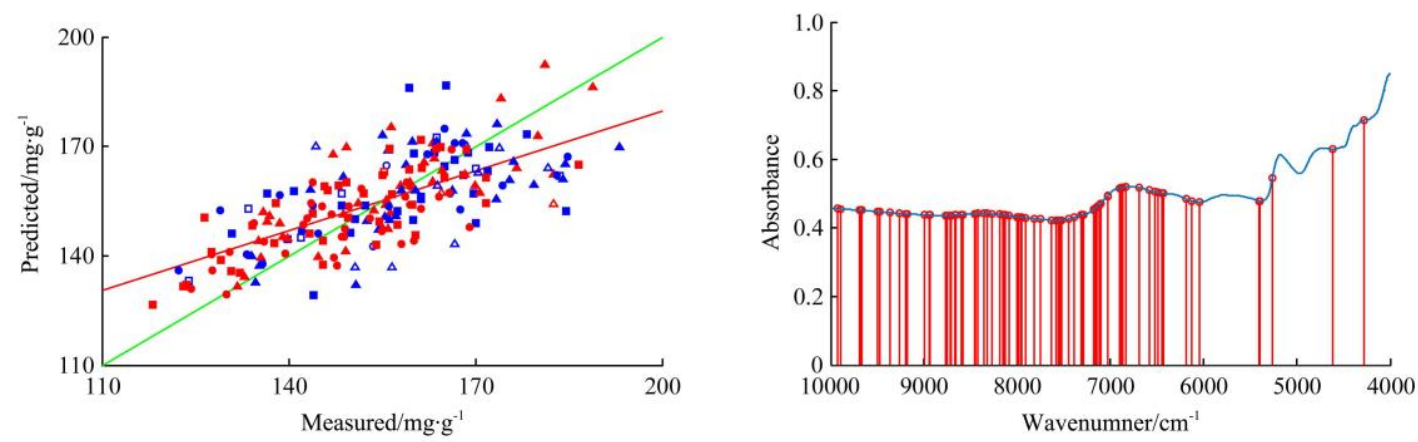

c. Lignin

Note: CARS, competitive adaptive reweighted sampling; PLS, partial least squares; the blue and red colours represent Japonica and Indica rice straw, respectively; the shapes of circle, triangle, and square represent early-season, middle-season, and late-season rice straw, respectively; the solid and hollow symbols represent irrigated and rain fed rice straw, respectively.

Figure 2 Optimal combinations of wavenumbers selected by CARS and the results of the CARS-PLS models for lignocellulose 

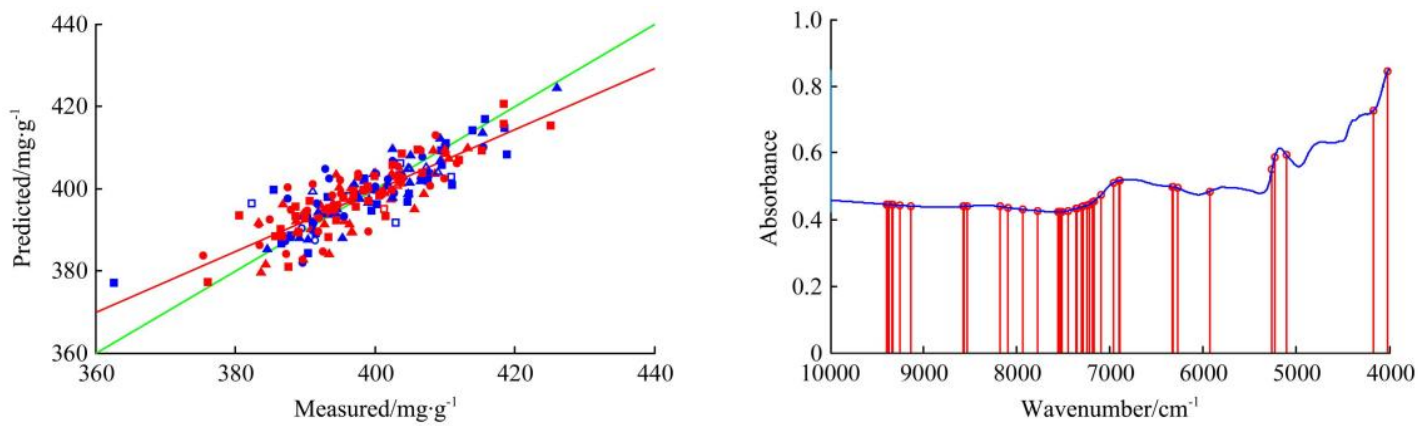

a. Carbon
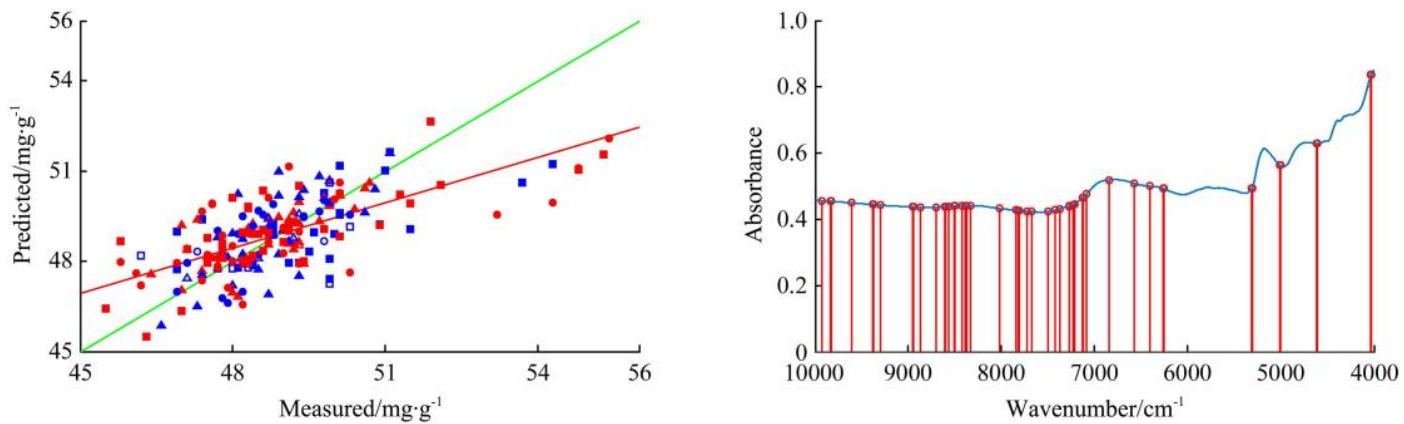

b. Hydrogen
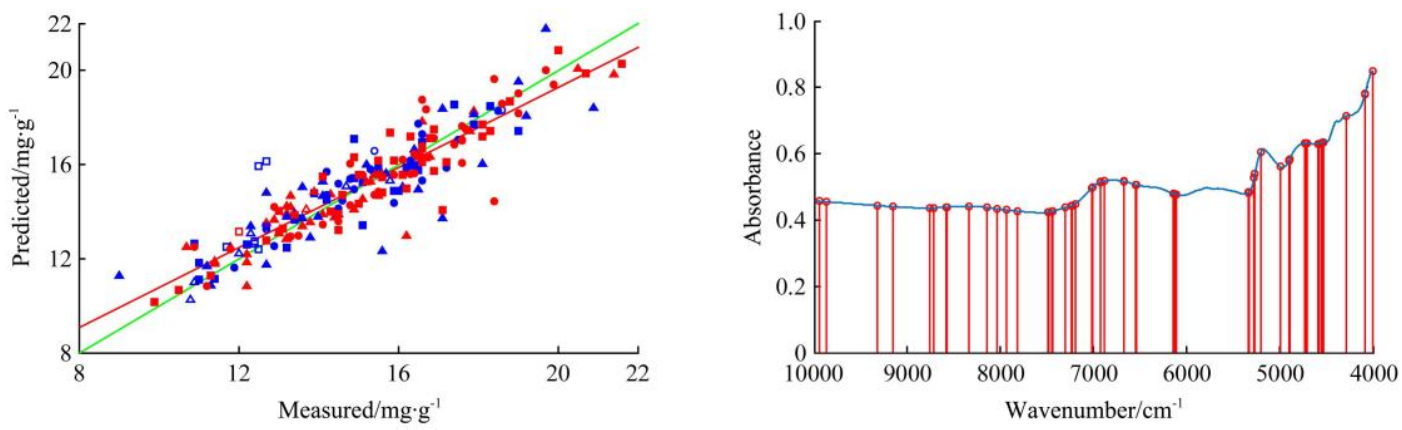

c. Nitrogen
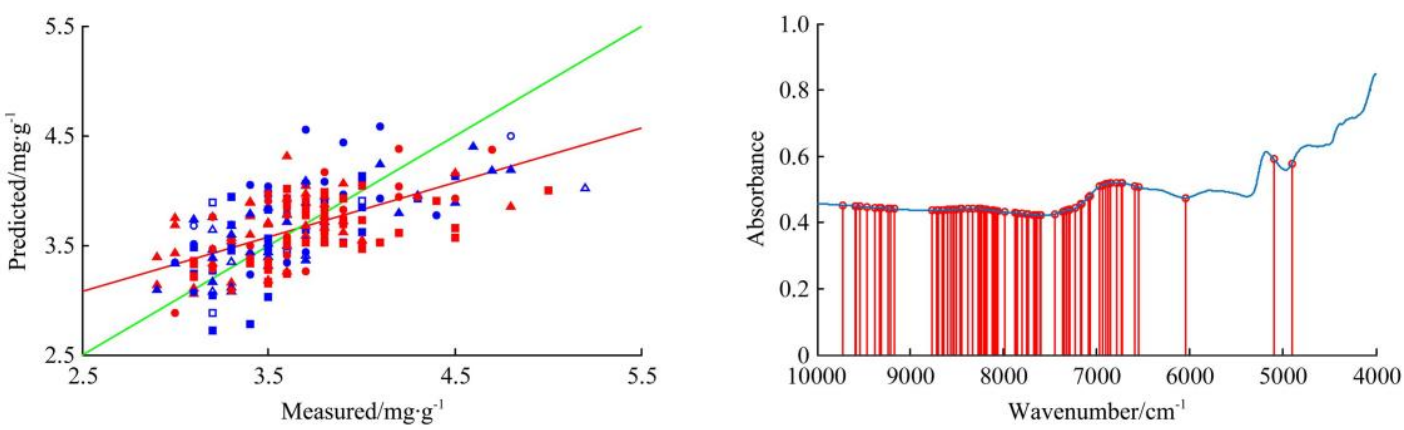

d. Sulphur

Note: CARS, competitive adaptive reweighted sampling; PLS, partial least squares; the blue and red colours represent Japonica and Indica rice straw, respectively; the shapes of circle, triangle, and square represent early-season, middle-season, and late-season rice straw, respectively; the solid and hollow symbols represent irrigated and rain fed rice straw, respectively.

Figure 3 Optimal combinations of wavenumbers selected by CARS and the results of the CARS-PLS models for organic elements

\section{Discussion}

According to the results of the wet-chemical analysis, the mean contents of the lignocellulose and organic elements of 364 rice straw samples were Cel $(398.9 \mathrm{mg} / \mathrm{g})$, Hem $(147.5 \mathrm{mg} / \mathrm{g})$, Lig (154.4 mg/g), C (398.4 mg/g), H (49.6 mg/g), N (15.3 mg/g) and S $(3.8 \mathrm{mg} / \mathrm{g})$, which are comparable with those of American rice straw $^{[9]}$, e.g., Cel (320-470 mg/g), Hem (190-270 mg/g), and Lig $(50-240 \mathrm{mg} / \mathrm{g})$. The contents of organic elements lie within the average range of Chinese biomass ${ }^{[10]}$, i.e., C $(385.2-501.5 \mathrm{mg} / \mathrm{g})$,
$\mathrm{H}(61.3-83.6 \mathrm{mg} / \mathrm{g}), \mathrm{N}(1.1-20.6 \mathrm{mg} / \mathrm{g})$, and $\mathrm{S}(0.2-3.9 \mathrm{mg} / \mathrm{g})$. The $\mathrm{S}$ content of the rice straw involved in the current study is higher than the average level in the U.S. $(1.0 \mathrm{mg} / \mathrm{g})$, Thailand $(1.0-2.9 \mathrm{mg} / \mathrm{g})$, and Egypt $(1.0 \mathrm{mg} / \mathrm{g})^{[11-13]}$.

In terms of the spectral results of rice straw, a weak and broad absorption peak around $8223 \mathrm{~cm}^{-1}$ has been assigned to $\mathrm{C}-\mathrm{H}$ stretching $\left(2^{\text {nd }}\right.$ overtone), and the absorption in the region $7042-6250 \mathrm{~cm}^{-1}$ has been associated with $\mathrm{O}-\mathrm{H}$ stretching for $\mathrm{Hem} / \mathrm{Cel}$, C-H stretching for Lig, and $\mathrm{N}-\mathrm{H}$ stretching for protein $^{[14]}$. The signal in the region of $6172-5617 \mathrm{~cm}^{-1}$ has been 
attributed to $\mathrm{C}-\mathrm{H}$ stretching $\left(1^{\text {st }}\right.$ overtone) for $\mathrm{Lig} / \mathrm{Cel} / \mathrm{Hem}{ }^{[15,16]}$. The noticeable peak at approximately $5200 \mathrm{~cm}^{-1}$ has been attributed to $\mathrm{O}-\mathrm{H}$ stretching and $\mathrm{C}=\mathrm{O}$ stretching ( $2^{\text {nd }}$ overtone) for $\mathrm{Cel} / \mathrm{Hem}^{[17]}$. The signal at around $4743 \mathrm{~cm}^{-1}$ has been ascribed to the combination band of $\mathrm{O}-\mathrm{H}$ stretching and $\mathrm{C}-\mathrm{O}$ stretching for $\mathrm{Hem}^{[18,19]}$. The peak at $4386 \mathrm{~cm}^{-1}$ has been proved to belong to $\mathrm{C}-\mathrm{H}$ stretching and $\mathrm{CH}_{2}$ deformation ${ }^{[17]}$. The range of 5500$4000 \mathrm{~cm}^{-1}$ contains rich information of $\mathrm{N}-\mathrm{H}^{[20]}$.

The evaluation parameters of the NIRS models showed, in terms of lignocellulose, the $R_{\text {cal }}^{2}$ of Lig is the highest, implying a good prediction of the Lig content, while the $R_{\text {cal }}^{2}$ of Hem is the lowest. The standard error of the laboratory (SEL) for Cel was $15.3 \mathrm{mg} / \mathrm{g}$. The RMSECV of the CARS-PLS model for Cel was $28.2 \mathrm{mg} / \mathrm{g}$. The RMSECV is less than two times $S E L$, meaning an accurate prediction for $\mathrm{Cel}^{[21]}$. The modelling result of Hem was the worst, but the $R S D$ value was still satisfactory $(12.40 \%)$. In the case of validation, the RMSEP values of Cel, Hem, and Lig were $25.4 \mathrm{mg} / \mathrm{g}, 22.7 \mathrm{mg} / \mathrm{g}$, and $14.1 \mathrm{mg} / \mathrm{g}$, respectively, while the $R S D$ of Cel, Hem, and Lig were $6.43 \%, 15.40 \%$, and $9.16 \%$, respectively. These results are similar to the reported studies ${ }^{[2,4,5]}$. However, the lignocellulosic data for the reported NIRS models were obtained by the Van Soest method that is an indirect calculation method, while the NIRS models for lignocellulose developed in the current study were based on the data from the direct NREL measurements. In terms of organic elements, the $R_{\text {cal }}^{2}$ values for $\mathrm{N}$ and $\mathrm{C}$ were 0.86 and 0.77 , respectively, identifying the effectiveness of the developed models. The RSD for $\mathrm{H}$ was $2.37 \%$, implying a good prediction. The modelling result for $\mathrm{S}$ was the poorest, but the $R S D$ was not too bad (10.26\%). In the case of validation, the RMSEP values of $\mathrm{C}, \mathrm{H}, \mathrm{N}$, and $\mathrm{S}$ were $8.1 \mathrm{mg} / \mathrm{g}, 3.4 \mathrm{mg} / \mathrm{g}, 1.4 \mathrm{mg} / \mathrm{g}$, and $0.5 \mathrm{mg} / \mathrm{g}$ respectively. These results are similar to the reported studies ${ }^{[3]}$. Either for lignocellulose or for organic elements, given a wide variety of rice straw involved in the current study, the performances of all the models are considered satisfactory.

Comparison between the CARS-PLS and PLS models showed that the accuracy of the CARS-PLS models for Hem, Lig, C, H, N, and $\mathrm{S}$ is much higher than that of the PLS models, and the accuracy of the CARS-PLS model for Cel is similar with that of the PLS model. The reason for the higher accuracy of the CARS-PLS models might be that the selection of the optimal combinations of wavenumbers by CARS enhanced the signal of chemical bonds and thereby improved the predictive efficiency. Given the high accuracy of the CARS-PLS models, they could be used for predicting the contents of the lignocellulose and organic elements of a wide variety of rice straw, which featured different rice subspecies, growing seasons, and growing environments.

Additionally, the $\mathrm{N}$ content was predicted precisely by the CARS-PLS model. The $\mathrm{N}$ content of rice straw is always a major concern, because it would dramatically affect the nutrient profiles of soil ${ }^{[22]}$, greenhouse gas emissions from rice fields ${ }^{[23]}$, and biogas production that uses rice straw as a feedstock ${ }^{[24]}$. Therefore, the good performance of the CARS-PLS model for modelling the $\mathrm{N}$ content enabled it a considerable potential in practice.

\section{Conclusions}

First, the differences of lignocellulose and organic elements of rice straw related to different rice subspecies, growing seasons, and environments were tested by multivariate analysis of variance. Statistic results showed that the Cel content had significant differences among different growing seasons $(p<0.01)$, and the contents of $\mathrm{Cel}$ and $\mathrm{N}$ had significant differences between different growing environments $(p<0.01)$. Secondly, NIRS models were built by the PLS algorithm to analyse the contents of the lignocellulose and organic elements of rice straw. However, these NIRS models were not satisfactory because there was redundant and interferential information in the spectra. Subsequently, the CARS algorithm was used to select optimal combinations of wavenumbers, and then combined with PLS to build CARS-PLS models based on the optimal combinations. The modelling results showed that the accuracy of the CARS-PLS models for Hem, Lig, $\mathrm{C}, \mathrm{H}, \mathrm{N}$, and $\mathrm{S}$ is much higher than that of the PLS models, possibly because the selection of the optimal combinations of wavenumbers by CARS enhanced the signal of chemical bonds and thereby improved the predictive efficiency. As a major contributor to the applications of rice straw, the $\mathrm{N}$ content was predicted precisely by the CARS-PLS model. Generally, the CARS-PLS models efficiently quantified the lignocellulose and organic elements of a wide variety of rice straw that featured different rice subspecies, growing seasons, and growing environments. The acceptable accuracy of the models allowed their further applications.

\section{Acknowledgements}

We would like to acknowledge the support given by the Innovation Team Project of the Ministry of Education (IRT_17R105), the China Agriculture Research System (CARS-36), and Program for Changjiang Scholars.

\section{[References]}

[1] Abraham A, Mathew A K, Sindhu R, Pandey A, Binod P. Potential of rice straw for bio-refining: An overview. Bioresour Technol., 2016; 215: 29-36. doi: org/10.1016/j.biortech.2016.04.011

[2] Jin S Y, Chen H Z. Near-infrared analysis of the chemical composition of rice straw. Ind Crop Prod., 2007; 26(2): 207-211. doi: 10.1016/ j.indcrop.2007.03.004

[3] Huang C, Han L, Yang Z, Liu X. Ultimate analysis and heating value prediction of straw by near infrared spectroscopy. Waste Manage., 2009; 29(6): 1793-1797. doi: 10.1016/j.wasman.2008.11.027

[4] Huang C, Han L J, Liu X, Ma L. The rapid estimation of cellulose, hemicellulose, and lignin contents in rice straw by near infrared spectroscopy. Energ Source Part A., 2010; 33(2): 114-120. doi: org /10.1080/15567030902937127

[5] Hattori T, Murakami S, Mukai M, Yamada T, Hirochika H, Ike M, et al. Rapid analysis of transgenic rice straw using near-infrared spectroscopy. Plant Biotechnol-Nar., 2012; 29: 359-366. doi: org/10.5511/plantbiotechnology.12.0501a

[6] Sluiter J B, Ruiz R O, Scarlata C J, Sluiter A D, Templeton D W. Compositional analysis of lignocellulosic feedstocks. 1. Review and Description of Methods. J Agric Food Chem., 2010; 58: 9043-9053. doi: 10.1021/jf1008023

[7] Roggo Y, Chalus P, Maurer L, Lema-Martinez C, Edmond A, Jent N. A review of near infrared spectroscopy and chemometrics in pharmaceutical technologies. J Pharmaceut Biomed., 2007; 44: 683-700. doi: org/10. 1016/j.jpba.2007.03.023

[8] Huang C J, Han L J, Yang Z L, Liu X. Prediction of heating value of straw by proximate data, and near infrared spectroscopy. Energ Convers Manage., 2008; 49(12): 3433-3438. doi: 10.1016/j.enconman.2008. 08.020

[9] Belal E B. Bioethanol production from rice straw residues. Braz J Microbiol., 2013; 44: 225-234. doi: 10.1590/S1517-83822013000100033

[10] Liao C P, Wu C Z, Yany Y J, Huang H T. Chemical elemental characteristics of biomass fuels in China. Biomass Bioenerg., 2004; 27(2) 119-130. doi: 10.1016/j.biombioe.2004.01.002

[11] Banta S, Mendoza C. Organic Matter and Rice. Manila, Philippines: International Rice Research Institute, 1984.

[12] Garivait S, Chaiyo U, Patumsawad S, Deakhuntod J. Physical and chemical properties of thai biomass fuels from agricultural residues. The 
2nd Joint International Conference on Sustainable Energy and Environment. 2006; 1-23.

[13] Stahl R, Ramadan A B. Fuels and chemicals from rice straw in Egypt. Forschungszentrum Karlsruhe, FZKA-7361, 2007. doi: 10.5445/IR/2700 69896

[14] Niu W J, Huang G Q, Liu X, Chen L J, Han L J. Chemical composition and calorific value prediction of wheat straw at different maturity stages using near-infrared reflectance spectroscopy. Energ Fuel., 2014; 28(12): 7474-7482. doi: 10.1021/ef501446r

[15] Lande S, Riel S V, Høibø O A, Schneider M H. Development of chemometric models based on near infrared spectroscopy and thermogravimetric analysis for predicting the treatment level of furfurylated Scots pine. Wood Sci Technol., 2010; 44(2): 189-203. doi: org/10.1007/s00226-009-0278-x

[16] Sun B L, Liu J L, Liu S J, Yang Q. Application of FT-NIR-DR and FT-IR-ATR spectroscopy to estimate the chemical composition of bamboo (Neosinocalamus affinis Keng). Holzforschung, 2011; 65(5): 689-696. doi: org/10.1515/hf.2011.075

[17] He W M, Hu H R. Prediction of hot-water-soluble extractive, pentosan and cellulose content of various wood species using FT-NIR spectroscopy. Bioresour Technol., 2013; 140: 299-305. doi: org/10.1016 /j.biortech. 2013.04.115

[18] Wójciak A, Kasprzyk H, Sikorska E, Krawczyk A, Sikorski M, Wesełucha-Birczyńska A. FT-Raman, FT-infrared and NIR spectroscopic characterization of oxygen-delignified kraft pulp treated with hydrogen peroxide under acidic and alkaline conditions. Vib Spectrosc., 2014; 71:
62-69. doi: org/10.1016/j.vibspec.2014.01.007

[19] Li X L, Sun C J, Zhou B X, He Y. Determination of hemicellulose cellulose and lignin in moso bamboo by near infrared spectroscopy. Sci Rep., 2015; 5: 17210. doi: org/10.1038/srep17210

[20] Workman J, Weyer L. Practical guide to interpretive near-infrared spectroscopy. Boca Raton, FL, USA: CRC Press, Inc.2007.

[21] Urbano-Cuadrado M, Castro L D, Pérez-Juan P M, García-Olmo J, Gómez-Nieto M A. Near infrared reflectance spectroscopy and multivariate analysis in enology: determination or screening of fifteen parameters in different types of wines. Anal Chim Acta, 2004; 527: 81-88. doi: org/10.1016/j.aca.2004.07.057

[22] Li J, Tian X H, Wang S X, Ba Y L, Li Y B, Zheng X F. Effects of nitrogen fertilizer reduction on crop yields,soil nitrate nitrogen and carbon contents with straw returning. Journal of Northwest A \& F University: Natural Science Edition, 2014; 42: 137-143. (in Chinese)

[23] Xia L L, Xia Y Q, Ma S T, Wang J Y, Wang S W, Zhou W, et al Greenhouse gas emissions and reactive nitrogen releases from rice production with simultaneous incorporation of wheat straw and nitrogen fertilizer. Biogeosciences, 2016; 13(15): 4569-4579. doi: org/10.5194/ bg-13-4569-2016

[24] Valdez-Vazquez I, Torres-Aguirre G J, Molina C, Ruiz-Aguilar G M L. Characterization of a lignocellulolytic consortium and methane production from untreated wheat straw: Dependence on nitrogen and phosphorous content. BioResources, 2016; 11(2): 4237-4251. doi: 10.15376/biores. 11.2.4237-4251 